\title{
Erratum to: Cardiac risk assessment in asymptomatic diabetes: Combining different imaging modalities and surrogate markers?
}

\author{
Arthur J. H. A. Scholte, MD, PhD
}

\section{ERRATUM TO: J NUCL CARDIOL}

\section{DOI 10.1007/S12350-01 1-9366-Z}

The original article was published with an error in the first word of the subtitle, which should be "Combining" as shown in this erratum.

The online version of the original article can be found under doi: 10.1007/s12350-011-9366-z.

From the Department of Cardiology, Leiden University Medical Center, Leiden, The Netherlands.

Reprint requests: Arthur J. H. A. Scholte, MD, PhD, Department of Cardiology, Leiden University Medical Center, Albinusdreef 2, PO Box 9600, 2300 RC Leiden, The Netherlands; a.j.h.a.scholte@ lumc.nl.

J Nucl Cardiol 2011;18:801

$1071-3581 / \$ 34.00$

Copyright (C) 2011 American Society of Nuclear Cardiology.

doi:10.1007/s12350-011-9393-9 